\title{
Relative Efficiency of Pitfall Trapping vs. Nocturnal Hand Collecting in Assessing Soil-Dwelling Spider Diversity along A Structural Gradient of Neotropical Habitats
}

\author{
Kaïna Privet ${ }^{1, *,+} \oplus$, Vincent Vedel ${ }^{2,3,+}$, Claire Fortunel ${ }^{4}{ }^{\oplus}$, Jérôme Orivel ${ }^{5}{ }^{\oplus}$, \\ Quentin Martinez ${ }^{6}$, Axel Cerdan ${ }^{5,7}$, Christopher Baraloto ${ }^{8} \mathbb{D}$ and Julien Pétillon ${ }^{1}$ \\ 1 CNRS, Ecobio (Ecosystèmes, biodiversité, évolution), Université de Rennes, UMR 6553, F-35000 Rennes, \\ France; julien.petillon@univ-rennes1.fr \\ 2 Laboratoire d'Entomologie Entobios, Rainstrasse 1, 77694 Kehl, Germany; vinsvedel@gmail.com \\ 3 UMR EcoFoG (Agroparistech, CIRAD, CNRS, INRA, Université des Antilles), Campus Agronomique, \\ Université de Guyane, BP 316, 97379 Kourou CEDEX, France \\ 4 AMAP (botAnique et Modélisation de l'Architecture des Plantes et des végétations), CIRAD, CNRS, INRAE, \\ IRD, TA A51/PS2, Boulevard de la Lironde, Université de Montpellier, 34398 Montpellier CEDEX 5, France; \\ claire.fortunel@ird.fr \\ 5 CNRS, UMR EcoFoG (Agroparistech, CIRAD, INRA, Université de Guyane, Université des Antilles), \\ Campus Agronomique, BP 316, 97379 Kourou CEDEX, France; jerome.orivel@cnrs.fr (J.O.); \\ axel.cerdan@ecofog.gf (A.C.) \\ 6 Institut des Sciences de l'Evolution (ISEM, UMR 5554), Université de Montpellier, Place E. Bataillon - CC064, \\ 34095 Montpellier CEDEX 5, France; quentinmartinezphoto@gmail.com \\ 7 Laboratoire EDB (CNRS, IRD, Université de Toulouse), bâtiment 4R1, 118, route de Narbonne, \\ 31062 Toulouse CEDEX 9, France \\ 8 International Center for Tropical Botany, Department of Biological Sciences, Florida International University \\ 11200 S.W. 8th Street, Miami, FL 33199, USA; cbaraloto@fiu.edu \\ * Correspondence: kprivet@hotmail.fr or kaina.privet@univ-rennes1.fr \\ + These authors contributed equally to the work.
}

Received: 17 January 2020; Accepted: 14 February 2020; Published: 19 February 2020

\begin{abstract}
Assessing spider diversity remains a great challenge, especially in tropical habitats where dozens of species can locally co-occur. Pitfall trapping is one of the most widely used techniques to collect spiders, but it suffers from several biases, and its accuracy likely varies with habitat complexity. In this study, we compared the efficiency of passive pitfall trapping versus active nocturnal hand collecting (NHC) to capture low understory-dwelling spider taxonomical (morpho-species) and functional (hunting guilds) diversity along a structural gradient of habitats in French Guiana. We focused on four habitats describing a structural gradient: garden to the orchard to the forest edge to the undisturbed forest. Overall, estimated morpho-species richness and composition did not vary consistently between habitats, but abundances of ground-hunting spiders decreased significantly with increasing habitat complexity. We found habitat-dependence differences in taxonomic diversity between sampling strategies: NHC revealed higher diversity in the orchard, whereas pitfalls resulted in higher diversity in the forest. Species turnover resulted in high dissimilarity in species composition between habitats using either method. This study shows how pitfall trapping is influenced by habitat structure, rendering this sampling method incomplete for complex, tropical environments. However, pitfall traps remain a valuable component of inventories because they sample distinct assemblage of spiders.
\end{abstract}

Keywords: Araneae; Guiana shield; sampling methods; diversity indices; functional diversity; species richness; turnover 


\section{Introduction}

Spiders constitute a mega-diverse taxon, with more than 48,000 species described to date [1] and still many new species found every year. To get reliable estimates of local spider diversity, ecologists and conservationists need a robust sampling protocol, i.e., standardized (repeatable in space and time, without introducing bias), and optimized (with a maximized ratio of sampling effort by collected diversity) for realistic sampling given time and resource constraints [2-4]. To achieve such a standardized and optimized sampling protocol, the selection of cost-effective complementary methods is a critical issue [5]. Previous work on sampling protocol optimization was mainly conducted in Mediterranean and temperate systems (see [3,4]), but few studies have compared methods in highly diverse systems such as tropical forests [6,7]. Yet, it remains unclear which sampling protocol would provide reliable estimates of spider diversity in tropical systems.

Because spiders have developed a wide range of hunting strategies (e.g., ambushing, wandering, web building, door trapping) and inhabit varied habitats and vegetation strata (from the ground to canopy), several sampling methods need to be integrated to get a reliable description of the whole assemblage. Nevertheless, the number of collecting methods should be limited to minimize the complexity of a sampling protocol and to maximize its repeatability.

The objective of this study is, therefore, to evaluate the robustness of sampling methods in tropical forests. In that respect, we focused on tropical low understory-dwelling spiders because there is less consensus to sample this stratum in forests despite its lower spider diversity compared to other strata $[6,7]$.

Previous studies on low understory-dwelling spiders showed that this stratum needs to be studied with special care in order to obtain representative estimates [8-10], especially because sampled diversity changes with the sampling method [11,12].

In tropical forests, however, there is no consistency between the methods used to sample low understory-dwelling spiders. For example, Vedel et al. [13] used hand collection and litter sifting, Malumbres-Olarte et al. [6] used hand collection, cryptic searching, and pitfall traps, and Privet et al. [7] used pitfall traps and litter sifting.

Pitfall trapping is the most widely used arthropod sampling technique to collect spiders worldwide [12,14-16]. This method was shown to be efficient in catching ground-dwelling spiders in a variety of ecosystems, including temperate forests [17], Mediterranean shrublands [3], agro-systems, and grasslands [11,18], and bare grounds [19]. However, pitfall traps appear to be less efficient in tropical forests $[6,7,13]$, and they may suffer from several important biases, including the under-studied effect of habitat structure [20,21].

Together with litter sifting (specially designed for small and low mobile species: [7]), nocturnal hand collecting (NHC) is an alternative method to sample low understory-dwelling spiders. This method was found to be efficient by Azevedo et al. [5], in particular, as it shows no bias between day and night spider diversity sampling in tropical forests $[7,22]$. Yet, depending on the collectors' experience, NHC is cheap and requires less effort than pitfall traps $[5,23]$.

Hence, it is still unclear whether pitfall trapping should be used to perform a standardized protocol, or whether nocturnal hand collecting should be included to develop an optimized protocol. Moreover, although the efficiency of pitfall trap sampling is likely to be influenced by habitat structure, as with other passive methods, no study to date has assessed how its efficiency could change along a structural gradient of habitat.

Here we compare the efficiency of two widely used sampling techniques, pitfall traps, and NHC, to capture taxonomic and functional diversity of low understory-dwelling spider assemblages along a broad gradient of tropical habitats in French Guiana. We hypothesize that the sampling efficiency of passive methods (i.e., pitfall traps) would decrease when habitat structural complexity increases [20]. In contrast, we predict little variation in sampling efficiency for the active method of NHC [21].

More precisely, we expect a difference in the estimated taxonomic diversity between methods to increase along the increasing gradient of habitat structural complexity (tested by comparing rarefaction 
curves between methods habitat by habitat). Second, we expect species composition of spider assemblages to differ between methods and vary more with habitat structure with pitfall traps than with NHC (tested by determining beta diversity between methods per habitat and beta diversity between habitats per method). Finally, we hypothesize that hunting guilds diversity (a proxy of the functional diversity assessed by guilds composition and relative abundances per method per habitat) would be more affected by changes in habitat structural complexity with pitfall traps than with NHC.

\section{Materials and Methods}

\subsection{Sites}

To compare the efficiency of low understory-dwelling spider sampling methods along a structural gradient of Neotropical habitats, we focused on four different land-use types along the road Degrad Saramaka, near Kourou, in French Guiana. The habitats sampled were: (i) home garden, (ii) small orchard after slash and burn, (iii) forest edge, and (iv) undisturbed tropical forest (see Table 1 for GPS [global positioning system] coordinates, pictures, and Corine Land Cover codes). The garden habitat had the least vegetation cover with mainly short cut grass, some herbaceous patches, a few ornamental flower bushes (Ixora sp. [species]), and some young trees such as mango trees. The orchard habitat was a lowland rain forest cut out and planted with tree species producing fruits (mango, banana, lemon, orange, cashew nut, coconut, and other palm trees), a variety of bushes (pineapple, spinach, and manioc) and some herbaceous cover. The forest edge was adjacent to a road and an open area such as gardens. It was $50 \mathrm{~m}$ deep into the vegetation, so its aspect was similar to forest areas. The forest was a primary lowland tropical rain forest area with the typical vegetation of seasonally flooded forest of coastal French Guiana. We established one plot of $50 \mathrm{~m} \times 50 \mathrm{~m}$ in each of the four land-use types, and inside an area of $20 \mathrm{~km}^{2}$ (Table 1) to limit changes in soil type and hydrological characteristics. The local climate is typically equatorial with a fairly constant temperature across the year (around $26.1^{\circ} \mathrm{C}$ with $1.3^{\circ} \mathrm{C}$ difference between the lowest and the highest temperature for 2001-2012) with high humidity divided into two main seasons: heavy rainfall between December and August and dry with few rains between September and November, giving an average annual precipitation about $283 \mathrm{~cm}$ per year [24].

Table 1. Coordinates and Corine Land Cover classes of the four habitats along the habitat complexity gradient. GPS: global positioning system.

\begin{tabular}{|c|c|c|c|c|}
\hline \multicolumn{5}{|l|}{ Habitats } \\
\hline & Garden & Orchard & Edge & Forest \\
\hline GPS coordinates & $5^{\circ} 04^{\prime} 43.3^{\prime \prime} \mathrm{N}$ & $5^{\circ} 04^{\prime} 58.6^{\prime \prime} \mathrm{N}$ & $5^{\circ} 04^{\prime} 15.0^{\prime \prime} \mathrm{N}$ & $5^{\circ} 04^{\prime} 11.4^{\prime \prime} \mathrm{N}$ \\
\hline GPS coorainates & $\begin{array}{c}52^{\circ} 40^{\prime} 36.8^{\prime \prime} \mathrm{W} \\
2430 \text { - Land }\end{array}$ & $52^{\circ} 41^{\prime} 47.3^{\prime \prime} \mathrm{W}$ & $52^{\circ} 41^{\prime} 33.8^{\prime \prime} \mathrm{W}$ & $52^{\circ} 41^{\prime} 48.1^{\prime \prime} \mathrm{W}$ \\
\hline $\begin{array}{l}\text { Corine Land } \\
\text { Cover } 2012 \text { code } \\
\text { and libellee }\end{array}$ & $\begin{array}{l}\text { principally occupied } \\
\text { by agriculture, with } \\
\text { significant areas of } \\
\text { natural vegetation }\end{array}$ & $\begin{array}{l}3111 \text { - Broad-leaved } \\
\text { forest }\end{array}$ & $\begin{array}{c}3111 \text { - Broad-leaved } \\
\text { forest }\end{array}$ & $\begin{array}{c}3111 \text { - Broad-leaved } \\
\text { forest }\end{array}$ \\
\hline
\end{tabular}

\subsection{Sampling Protocol}

In order to sample ground-dwelling spiders, we used circular pitfall traps and NHC. Following the COBRA protocol [4,15], we set up 25 pitfall traps (eight centimeters in diameter) in a grid of $5 \mathrm{~m} \times 5 \mathrm{~m}$ in each plot (five lines of five pitfalls spaced by $10 \mathrm{~m}$ across each $250 \mathrm{~m}^{2}$ plot). The pitfall traps were filled one-third full by ethylene glycol for killing and preserving specimens fallen in the traps. The pitfall traps remained active 15 days. In each plot, this method required a team of two 
people working two hours to install 25 pitfall traps and one hour to collect samples, resulting in a total effort of six person-hours per plot. While the pitfall traps were active, we sampled spiders using NHC along the lines traced by pitfalls. This method required two experienced persons sampling low understory with a headlamp for half an hour during night-time in each plot looking for moving spiders and eye-shine. This gave a sampling effort of one person-hour per plot for NHC. Sampling was conducted from the 15th to the 29th of July 2013, corresponding to the end of the raining season in French Guiana. The climate in July 2013 in Kourou oscillated between 28 to $33^{\circ} \mathrm{C}$, with an average of $4.46 \mathrm{~mm}$ of precipitation per day [25].

\subsection{Taxonomy}

Individuals were sorted and identified at the species level, defining morpho-species when there were no matching species in the literature [13,26-28]. Spider samples, separated by morpho-species from each sampling technique, were stored in $70 \%$ ethanol. When juvenile spiders were old and characteristic enough to be identified at the species level, we included them. All spiders are deposited within the reference collections of the UMR EcoFoG, Kourou (French Guiana).

\subsection{Hunting Guilds}

Trait functions have not been explicitly tested for spiders, especially in tropical habitats, and using traits when there is no evidence for their functionality runs the risk of attributing patterns in community functional structure to false mechanisms [29]. Here we assessed functional diversity by assigning hunting guilds to genera and families. We are aware that guilds describe more a group of species than a functional attribute per se [30] and that guild classification at the family or genus level does not integrate inter- nor intraspecific variability [31], which are important in structuring assemblages. We followed the hunting guilds classification described in Cardoso et al. [31], except for Trechaleidae placed in specialists by Cardoso et al. [31] and described as hunters by Dias et al. [32]. The guilds were the following: (1) sensing, (2) sheet, (3) space, (4) orb-web weavers; (5) specialists; (6) ambush, (7) ground, and (8) other hunters.

\subsection{Data Analysis}

The 25 pitfall traps per habitat were pooled to make pitfall samples comparable to one hour NHC per habitat (following [6] methods and results). Taxonomic diversity per sampling method was assessed using rarefaction and extrapolation curves based on sample coverage [33,34]. We characterized the taxonomic alpha diversity of spider communities using complementary species and abundance-based indices: (i) taxonomic richness, (ii) Shannon, and (iii) Simpson diversities [33]. Analyses were completed using the R-based iNEXT package [33,35]. Extrapolations were realized using the asymptotic Chao1 estimator [36]. 95\% confidence intervals (CI) were calculated, and non-overlapping of CI indicates a difference at a level of 5 percent between expected diversities [33]. Changes in species composition (taxonomic beta diversity) (i) between methods within a habitat and (ii) between habitats per method were assessed by computing pair-wise dissimilarities on abundance data using the Bray indices family and separating the turnover and nestedness-resultant components of taxonomic beta diversity using the betapart $R$ package $[37,38]$. Guilds composition and relative abundances were compared between methods and habitats (i.e., pitfall garden vs. NHC garden; pitfall orchard vs. NHC orchard, etc.). Changes in guild composition were tested by statistically comparing the relative abundance of the dominant guilds among habitats using $\chi^{2}$ tests. All analyses were conducted using the $\mathrm{R}$ software version 3.4.3 [39].

\section{Results}

We sampled a total of 355 spiders (213 adults and 142 juveniles) representing 18 families and 40 morpho-species (see Table S1 for composition). Similar total numbers of individuals were collected by both methods, 174 by pitfall traps and 181 by NHC. 
Among the 18 morpho-species that were not singletons, four $(22 \%)$ were collected by both methods. The NHC technique collected specimens belonging to 28 morpho-species from 11 families and representing seven hunting guilds (ground, other and ambush hunters, sheet, orb, sensing web weavers and specialists). Pitfall traps sampled spiders from 18 morpho-species from 11 families representing four hunting guilds (ground hunters, other hunters, sensing web weavers, and specialists).

Patterns of taxonomic alpha diversity were consistent between diversity metrics (i.e., species richness, Shannon and Simpson indices); taxonomic alpha diversity was significantly higher in the orchard but lower in the forest when using hand-collection compared to a pitfall, and it showed no differences between the methods in the garden and edge (Figure 1). Yet, taxonomic alpha diversity did not consistently vary with habitat complexity.
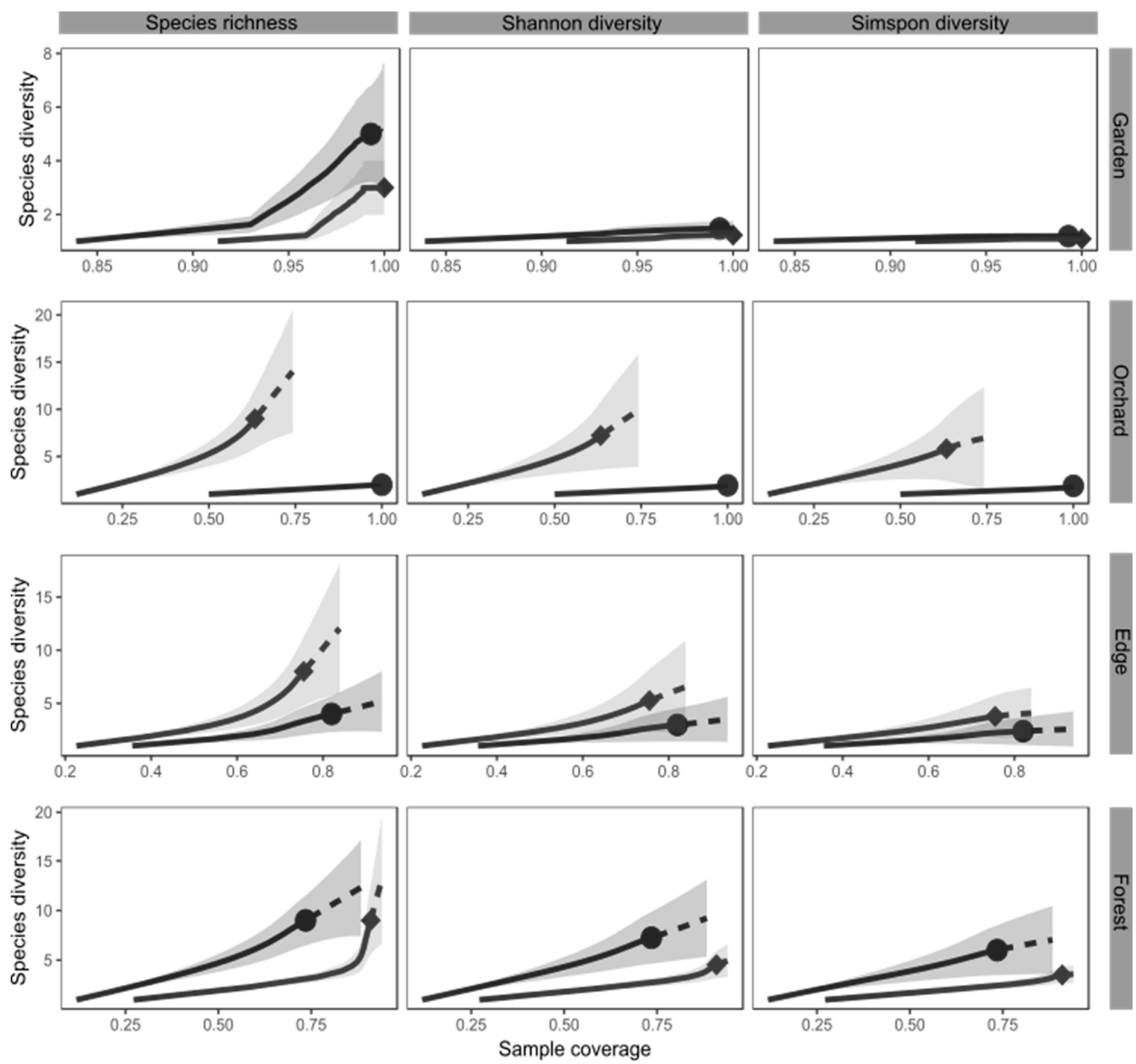

Nocturnal hand collecting

Figure 1. Estimated taxonomic diversity (species richness, Shannon, and Simpson diversities) in all four habitats for each sampling method. 95\% confidence intervals are represented in a light color and were obtained by 200 bootstrap replications. Plain lines represent interpolated diversity, whereas dotted lines extrapolated.

Species composition collected by the two methods was almost completely dissimilar. This dissimilarity was mainly due to species turnover in all habitats, except in gardens where assemblage composition was much more similar between methods. In this case, the few differences 
were linked to assemblage nestedness (Table 2). Assemblages were almost completely dissimilar among habitats for both methods, and this dissimilarity was mostly due to species turnover (Table 3 ).

Table 2. Species composition dissimilarity and its decomposition by habitat between pitfall traps vs. nocturnal hand-collecting $(\beta$ : beta diversity $=$ total dissimilarity between pitfall and NHC; $\beta_{\text {TURN }}$ : partition of the beta diversity linked to turnover; $\beta_{\mathrm{NEST}}$ : partition of the beta diversity linked to nestedness).

\begin{tabular}{ccccc}
\hline Habitat & Garden & Orchard & Edge & Forest \\
\hline $\boldsymbol{\beta}$ & 0.22 & 1 & 0.93 & 0.81 \\
$\boldsymbol{\beta}_{\text {TURN }}$ & 0.05 & 1 & 0.9 & 0.61 \\
$\boldsymbol{\beta}_{\text {NEST }}$ & 0.17 & 0 & 0.03 & 0.20 \\
\hline
\end{tabular}

Table 3. Decomposition of beta diversity among habitats and by sampling method ( $\beta$ : beta diversity; $\beta_{\text {TURN }}$ : partition of the beta diversity linked to turnover; $\beta_{\mathrm{NEST}}$ : partition of the beta diversity linked to nestedness).

\begin{tabular}{cccccccccc}
\hline Habitat & \multicolumn{3}{c}{ Garden } & \multicolumn{3}{c}{ Orchard } & \multicolumn{3}{c}{ Edge } \\
\hline Pitfall & $\beta$ & $\beta_{\text {TURN }}$ & $\beta_{\text {NEST }}$ & $\beta$ & $\beta_{\text {TURN }}$ & $\beta_{\text {NEST }}$ & $\beta$ & $\beta_{\text {TURN }}$ & $\beta_{\text {NEST }}$ \\
\hline Orchard & 1 & 1 & 0 & & & & & & \\
Edge & 0.97 & 0.8 & 0.17 & 1 & 1 & 0 & & & \\
Forest & 1 & 1 & 0 & 1 & 1 & 0 & 0.93 & 0.9 & 0.3 \\
\hline NHC & $\beta$ & $\beta_{\text {TURN }}$ & $\beta_{\text {NEST }}$ & $\beta$ & $\beta_{\text {TURN }}$ & $\beta_{\text {NEST }}$ & $\beta$ & $\beta_{\text {TURN }}$ & $\beta_{\text {NEST }}$ \\
\hline Orchard & 0.9 & 0.68 & 0.22 & & & & & & \\
Edge & 1 & 1 & 0 & 1 & 1 & 0 & & & \\
Forest & 1 & 1 & 0 & 1 & 1 & 0 & 0.89 & 0.8 & 0.09 \\
\hline
\end{tabular}

Guild composition significantly changed among habitats for both methods when considering pitfall traps and NHC separately ( $\chi^{2}$ tests, $6 \mathrm{df}, \chi^{2}=403.97$, and $\chi^{2}=274.29, p<0.001$, respectively) with a replacement of ground hunters by other hunters and web builders. On the other hand, patterns of guild relative abundance differed between methods only for the orchard and forests (Figure 2).

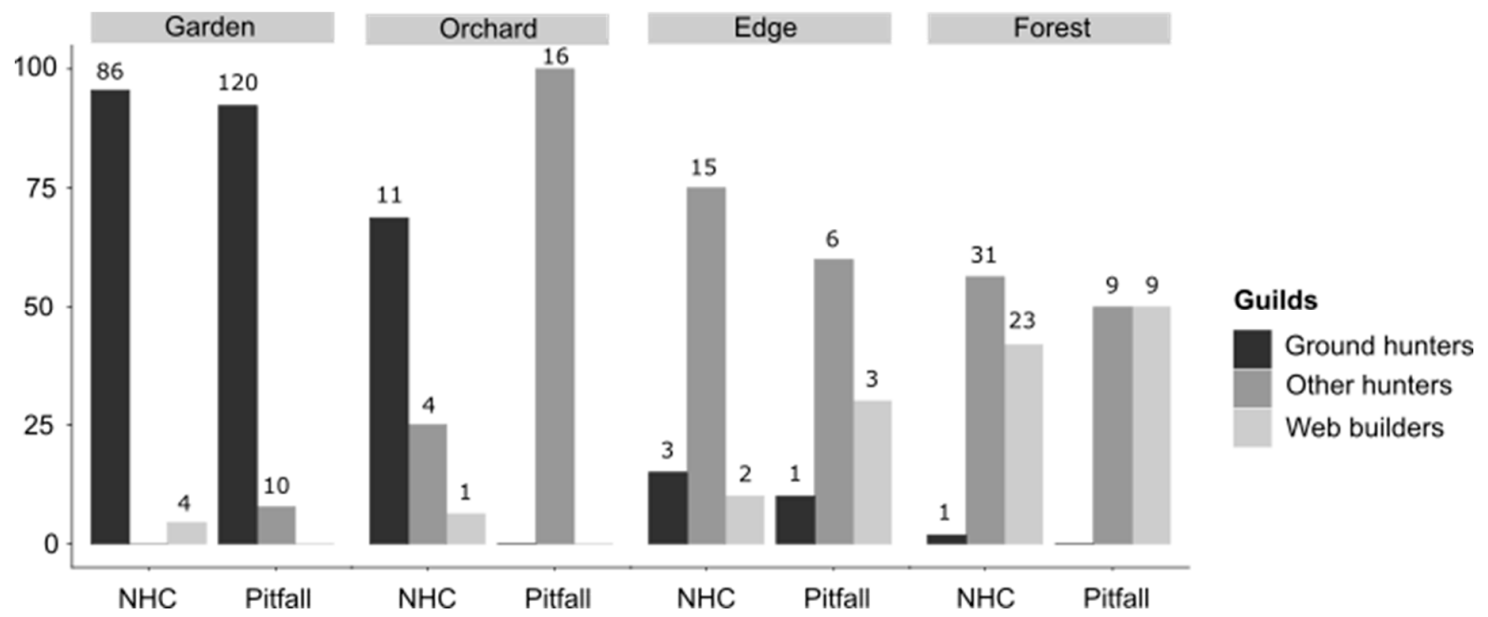

Figure 2. Relative abundance in hunting guilds along the structural gradient of habitats collected by Nocturnal Hand Collecting (NHC) and pitfall traps. For simplification purpose, we grouped guilds as follows: (1) ground hunters: 'ground hunters', (2) other hunters regroups the 'other hunters', 'ambush hunters' and 'specialists' guilds, and (3) web builders: 'sensing-web weavers, 'sheet-web weavers, 'space web weavers, and 'orb-web weavers'. Absolute numbers are presented above each bar. 


\section{Discussion}

In this study, we compared for the first time the efficiency of the two most common sampling methods to collect tropical soil-dwelling spiders, namely pitfall traps and Nocturnal Hand Collecting (NHC), across contrasting habitats in French Guiana. Our results showed that the difference between the two methods in capturing soil-dwelling spider taxonomical diversity varies according to the sampled habitat, though not consistently. Although we performed intensive sampling, the number of individuals was low, and the proportion of singletons was high, which is typical of tropical forests where many species are locally rare [40].

Differences in taxonomic alpha diversity between pitfall trapping and NHC did not significantly increase along the structural gradient of habitats. Contrary to our expectation that the difference of estimated taxonomic diversity between passive and active methods increases along the increasing gradient of habitat structural complexity, we actually found that taxonomic alpha diversities differed between methods only in orchard and forest. Our results in garden and forest edge are in line with two previous studies performed in the Mediterranean and temperate ecosystems [5,15] that both found pitfall traps and NHC to be both efficient methods to collect soil-dwelling spiders.

However, NHC was more efficient than pitfall traps to collect spider taxonomic alpha diversity in orchard, what may be due to the fact that pitfall traps would capture only species that actively hunt, while NHC would allow sampling species with a wider variety of hunting strategies (such as traps, silk nets or ambushing). Indeed, this was confirmed by our finding that NHC captures a more functional diversity of spiders than pitfall traps in this habitat. This result is in line with those of Sereda et al. [41], who found that hand-collection was better than pitfall traps for capturing ground-dwelling spider diversity in a temperate forest. Conversely, $\mathrm{NHC}$ was less efficient than pitfall traps to collect spider taxonomic richness in tropical rainforests. NHC efficiency relies on the sight of the person who samples, which would be reduced by the complexity and heterogeneity of the tropical rainforest habitat. The experience of collectors can also play an important role, which was not the case here with experienced collectors. Previous studies found that pitfall traps were unsuitable in estimating the diversity of ground-dwelling predators like spiders in tropical rainforests and other temperate woody habitats $[5-7,20,42]$. Although we choose to compare one-hour NHC (2 people, $1 / 2 \mathrm{~h}$ per person) with the pool of 25 pitfalls traps left 15 days on the field (versus five pitfall traps left for 5-8 days in [6]), we still observed that pitfall traps and NHC result in a similar number of sampled individuals. Comparing taxonomic alpha diversity relatively to sample completeness, our results suggest that an increase in sampling effort with NHC will not allow its efficiency to surpass those of pitfall traps. Hence, we suggest that neither pitfall traps nor NHC alone are sufficient for sampling the whole taxonomic alpha diversity of ground-dwelling spiders in Neotropical forests. Further methodological investigations comparing other sampling methods such as litter sifting [7] or hand collection in quadrats [23] are needed to estimate the diversity of ground-dwelling spiders in tropical rainforests better.

In addition, the taxonomic composition of spider assemblages was almost completely different when sampled by pitfall traps and NHC, and this dissimilarity was linked to species turnover except in the garden habitat. Contrary to our expectation, the difference in taxonomic composition between methods did not increase along the increasing gradient of structural habitat complexity. Moreover, taxonomic beta diversity was not more affected by changes in habitat complexity with pitfall traps. As NHC and pitfall traps do not sample the same species, both methods should be used concomitantly when aiming at inventorying spiders in tropical habitats. The fact that turnover of spider assemblages was driven by species turnover rather than by nestedness has already been reported from a large variety of habitats, such as temperate wet meadows, ponds and grasslands [43-45], forests [46], grey dunes [47] or African mountains [48]. In the garden habitat, assemblages sampled by NHC and pitfall traps were less dissimilar, and this dissimilarity was mostly linked to species nestedness: there were species and abundance loss between the methods, and no species replacement. Gardens are less complex, more open, and disturbed than other habitats. Its spider assemblage is very little diversified, as exemplified 
by the strong dominance of one single species (a Lycosidae). Consequently, pitfall traps and NHC sample nearly the same spider assemblage in this highly disturbed habitat, and may be interchangeable when sampling Neotropical garden, and other habitats with simple structure and low relative diversity. On the other hand, one should also consider that the small number of morpho-species common to both methods could be the result of the high proportion of singletons. As singleton proportion can be reduced by increasing sampling effort (although most tropical species are considered few abundant), the composition distinctiveness of these two methods could also decrease.

One intriguing aspect of our results concerns the proportion of male and female caught during the sampling. Pitfall traps are known to catch mature males to a higher degree than other sampling methods, including NHC, due to higher reproductive activity of males. Consequently, pitfall traps catch a larger percentage of identifiable spiders. If we confirm that pitfall traps caught more adult spiders, we, however, found that both methods catch more females than males.

Considering spider functional beta diversity (assessed by hunting guilds), dissimilarities between methods did not increase along the increasing gradient of habitat complexity, contrary to our prediction. NHC sampled higher guild richness in all habitats, which suggests that NHC is more efficient than pitfall trapping for collecting the overall functional diversity of soil-dwelling spiders in Neotropical habitats. However, both NHC and pitfall traps showed the same gradual change of guild composition across habitats, with a shift from ground hunters dominated-assemblages in garden habitat to assemblage dominated by 'other hunters' in forests (i.e., other hunters and ambush hunters, sensu [31]). Hence, even if pitfall traps collect fewer guilds, they still capture important elements of functional diversity. These results are in line with those found along an urban-rural transect in temperate regions [49], although functional changes were not systematically reported [50,51].

Unlike studies performed on other biomes, we suggest an optimized protocol using NHC to collect soil-dwelling spiders rather than pitfall traps in relatively simple tropical habitats (i.e., gardens, orchards, and edges) for ecological studies because it collects higher taxonomic and guild diversity and requires up to six-fold lesser sampling effort than pitfall traps, while still capturing similar abundances of soil-dwelling spiders and guilds shift along gradient. However, following Tourinho et al. [52], we suggest that NHC alone is not sufficient to provide a complete picture of spider assemblages in tropical habitats and should be used in association with beating tray methods. Besides, we showed that the efficiency of NHC is more limited than pitfall traps in complex habitats such as neotropical forests, which contradicts previous results (e.g., [6]). Knowing that pitfall traps are less efficient than litter sifting in the tropical forest [7], we suggest to combine NHC with litter sifting as based-methods for ecological studies of ground-dwelling spiders in this habitat, complemented by beating methods as well. However, we recommend studies with inventory purposes to use a combination of these methods as NHC and pitfall traps sample different species assemblages.

Supplementary Materials: The following are available online at http://www.mdpi.com/1424-2818/12/2/81/s1, Table S1: List of the morpho-species and their abundances caught by pitfall traps and by NHC in the four studied habitats.

Author Contributions: V.V. secured the funding; V.V and C.F. designed the sampling protocol; V.V., A.C. and Q.M. performed the sampling. Samples were sorted and identified by V.V. in the lab facilities offered by C.B. and J.O. Statistical analyses and writing were conducted by V.V., C.F., K.P., and J.P. All authors provided critical feedback and helped shape the research, analysis, and manuscript. Editing was realized by K.P. All authors have read and agreed to the published version of the manuscript.

Funding: This study was supported by an ECOPHYTODOM 2013 grant managed by the Direction of Food, Agriculture, and Forest (DAAF) of Guyane; collaborating with the cooperative BioSavane (Mélina Goasduff and Charlotte Gourmel). This work has benefited from an "Investissement d'Avenir" grant managed by Agence Nationale de la Recherche (CEBA, ref. ANR-10-LABX-25-01).

Acknowledgments: We are grateful to Cedran, Atzel and the Center National d'Etudes Spatiales who allowed the sampling to be done on their lands.

Conflicts of Interest: The authors declare no conflict of interest. The funders had no role in the design of the study; in the collection, analyses, or interpretation of data; in the writing of the manuscript, or in the decision to publish the results. 


\section{References}

1. World Spider Catalog World Spider Catalog. Version 20.0. Available online: http://wsc.nmbe.ch (accessed on 14 January 2020).

2. Coddington, J.A.; Griswold, C.E.; Silva Dàvila, D.; Peñaranda, E.; Larcher, S.F. Designing and testing sampling protocols to estimate biodiversity in tropical ecosystems. In The Unity of Evolutionary Biology: Proceedings of the fourth International Congress of Systematic and Evolutionary Biology; Dudley, E., Ed.; Dioscorides Press: Portland, OR, USA, 1991; pp. 44-60.

3. Cardoso, P.; Scharff, N.; Gaspar, C.; Henriques, S.S.; Carvalho, R.; Castro, P.H.; Schmidt, J.B.; Silva, I.; Szüts, T.; Castro, A.D.; et al. Rapid biodiversity assessment of spiders (Araneae) using semi-quantitative sampling: A case study in a Mediterranean forest. Insect Conserv. Divers. 2008, 1, 71-84. [CrossRef]

4. Cardoso, P.; Crespo, L.; Carvalho, R.; Rufino, A.; Henriques, S. Ad-Hoc vs. Standardized and Optimized Arthropod Diversity Sampling. Diversity 2009, 1, 36-51. [CrossRef]

5. Azevedo, G.H.; Faleiro, B.T.; Magalhães, I.L.; Benedetti, A.R.; Oliveira, U.; Pena-Barbosa, J.P.; Santos, M.T.; Vilela, P.F.; de Maria, M.; Santos, A.J. Effectiveness of sampling methods and further sampling for accessing spider diversity: A case study in a Brazilian Atlantic rainforest fragment. Insect Conserv. Divers. 2014, 7, 381-391. [CrossRef]

6. Malumbres-Olarte, J.; Scharff, N.; Pape, T.; Coddington, J.A.; Cardoso, P. Gauging megadiversity with optimized and standardized sampling protocols: A case for tropical forest spiders. Ecol. Evol. 2017, 7, 494-506. [CrossRef]

7. Privet, K.; Courtial, C.; Decaens, T.; Djoudi, E.A.; Vedel, V.; Ysnel, F.; Pétillon, J. Spider assemblage structure in a neotropical rainforest-inselberg complex: Ecological and methodological insights from a small-scale intensive survey. Trop. Ecol. 2018, 59, 21-34.

8. Adis, J. Problems for interpreting arthropod sampling with pitfall traps. Zool. Anziger Jena 1979, 202, $177-184$.

9. Döbel, H.G.; Denno, R.F.; Coddington, J.A. Spider (Araneae) Community Structure in an Intertidal Salt Marsh: Effects of Vegetation Structure and Tidal Flooding. Environ. Entomol. 1990, 19, 1356-1370. [CrossRef]

10. Semenina, E.E.; Anichkin, A.E.; Shilenkova, O.L.; Ermilov, S.G.; Tiunov, A.V. Rapid extraction of invertebrates from tropical forest litter using modified Winkler apparatus. J. Trop. Ecol. 2015, 31, 191-194. [CrossRef]

11. Churchill, T.B.; Arthur, J.M. Measuring Spider Richness: Effects of Different Sampling Methods and Spatial and Temporal Scales. J. Insect Conserv. 1999, 3, 287-295. [CrossRef]

12. Hancock, M.H.; Legg, C.J. Pitfall trapping bias and arthropod body mass: Pitfall bias and body mass. Insect Conserv. Divers. 2012, 5, 312-318. [CrossRef]

13. Vedel, V.; Rheims, C.; Murienne, J.; Brescovit, A.D. Biodiversity baseline of the French Guiana spider fauna. SpringerPlus 2013, 2, 361. [CrossRef] [PubMed]

14. Topping, C.J.; Sunderland, K.D. Limitations to the Use of Pitfall Traps in Ecological Studies Exemplified by a Study of Spiders in a Field of Winter Wheat. J. Appl. Ecol. 1992, 29, 485. [CrossRef]

15. Cardoso, P. Standardization and optimization of arthropod inventories- the case of Iberian spiders. Biodivers. Conserv. 2009, 18, 3949-3962. [CrossRef]

16. Brown, G.R.; Matthews, I.M. A review of extensive variation in the design of pitfall traps and a proposal for a standard pitfall trap design for monitoring ground-active arthropod biodiversity. Ecol. Evol. 2016, 6, 3953-3964. [CrossRef]

17. Sørensen, L.L.; Coddington, J.A.; Scharff, N. Inventorying and Estimating Subcanopy Spider Diversity Using Semiquantitative Sampling Methods in an Afromontane Forest. Environ. Entomol. 2002, 31, 319-330. [CrossRef]

18. Jansen, R.; Makaka, L.; Little, I.T.; Dippenaar-Schoeman, A. Response of ground-dwelling spider assemblages (Arachnida, Araneae) to Montane Grassland management practices in South Africa. Insect Conserv. Divers. 2013, 6, 572-589. [CrossRef]

19. Corti, R.; Larned, S.T.; Datry, T. A comparison of pitfall-trap and quadrat methods for sampling ground-dwelling invertebrates in dry riverbeds. Hydrobiologia 2013, 717, 13-26. [CrossRef]

20. Luff, M.L. Some features influencing the efficiency of pitfall traps. Oecologia 1975, 19, 345-357. [CrossRef]

21. Baars, M.A. Catches in pitfall traps in relation to mean densities of carabid beetles. Oecologia 1979, 41, 25-46. [CrossRef] 
22. Vedel, V.; Cerdan, A.; Martinez, Q.; Baraloto, C.; Petitclerc, F.; Orivel, J.; Fortunel, C. Day-time vs. night-time sampling does not affect estimates of spider diversity across a land use gradient in the Neotropics. J. Arachnol. 2015, 43, 413-416. [CrossRef]

23. Pétillon, J.; Leroy, B.; Djoudi, E.A.; Vedel, V. Small and large spatial scale coexistence of ctenid spiders in a neotropical forest (French Guiana). Trop. Zool. 2018, 31, 85-98. [CrossRef]

24. Merkel, A. Climat Kourou: Température Moyenne Kourou, Diagramme Climatique Pour Kourou-Climate-Data.Org. Available online: https://fr.climate-data.org/europe/france/guyane/kourou-29098/ (accessed on 30 August 2019).

25. Samson, T. Météo à Kourou En Juillet 2013. Available online: https://www.historique-meteo.net/ameriquedu-sud/guyane-francaise/kourou/2013/07/ (accessed on 30 August 2019).

26. Brescovit, A.D.; Bonaldo, A.B.; Bertani, R.; Rheims, C.A. Araneae. In Amazonian Arachnida and Myriapoda. Identification Keys to All Classes, Orders, Families, Some Genera, and Lists of Known Terrestrial Species; Adis, J., Ed.; Pensoft Publisher: Sofia, Moscow, 2002; pp. 303-343.

27. Levy, G. Spiders of the genera Micaria and Aphantaulax (Araneae, Gnaphosidae) from Israel. Isr. J. Zool. 2002, 48, 111-134. [CrossRef]

28. Prószyński, J. Monograph of the Salticidae (Araneae) of the World. Available online: http://salticidae.org/ salticid/main.htm (accessed on 21 February 2019).

29. Wong, M.K.L.; Guénard, B.; Lewis, O.T. Trait-based ecology of terrestrial arthropods. Biol. Rev. 2019, 94, 999-1022. [CrossRef] [PubMed]

30. Brousseau, P.-M.; Gravel, D.; Handa, I.T. On the development of a predictive functional trait approach for studying terrestrial arthropods. J. Anim. Ecol. 2018, 87, 1209-1220. [CrossRef] [PubMed]

31. Cardoso, P.; Pekár, S.; Jocqué, R.; Coddington, J.A. Global Patterns of Guild Composition and Functional Diversity of Spiders. PLoS ONE 2011, 6, e21710. [CrossRef] [PubMed]

32. Dias, S.C.; Carvalho, L.S.; Bonaldo, A.B.; Brescovit, A.D. Refining the establishment of guilds in Neotropical spiders (Arachnida: Araneae). J. Nat. Hist. 2009, 44, 219-239. [CrossRef]

33. Chao, A.; Gotelli, N.J.; Hsieh, T.C.; Sander, E.L.; Ma, K.H.; Colwell, R.K.; Ellison, A.M. Rarefaction and extrapolation with Hill numbers: A framework for sampling and estimation in species diversity studies. Ecol. Monogr. 2014, 84, 45-67. [CrossRef]

34. Chao, A.; Jost, L. Coverage-based rarefaction and extrapolation: Standardizing samples by completeness rather than size. Ecology 2012, 93, 2533-2547. [CrossRef]

35. Hsieh, T.C.; Ma, K.H.; Chao, A. iNEXT: An R package for rarefaction and extrapolation of species diversity (Hill numbers). Methods Ecol. Evol. 2016, 7, 1451-1456. [CrossRef]

36. Chao, A. Nonparametric estimation of the number of classes in a population. Scand. J. Stat. 1984, 11, 265-270.

37. Baselga, A.; Orme, C.D.L. betapart: An R package for the study of beta diversity. Methods Ecol. Evol. 2012, 3, 808-812. [CrossRef]

38. Baselga, A. Separating the two components of abundance-based dissimilarity: Balanced changes in abundance vs. abundance gradients. Methods Ecol. Evol. 2013, 4, 552-557. [CrossRef]

39. R Development Core Team R: A Language and Environment for Statistical Computing; R Foundation for Statistical Computing: Vienna, Austria, 2019.

40. Coddington, J.A.; Agnarsson, I.; Miller, J.A.; Kuntner, M.; Hormiga, G. Undersampling bias: The null hypothesis for singleton species in tropical arthropod surveys. J. Anim. Ecol. 2009, 78, 573-584. [CrossRef] [PubMed]

41. Sereda, E.; Blick, T.; Dorow, W.H.; Wolters, V.; Birkhofer, K. Assessing spider diversity on the forest floor: Expert knowledge beats systematic design. J. Arachnol. 2014, 42, 44-51. [CrossRef]

42. Maelfait, J.-P.; Baert, L. Contribution to the knowledge of the arachni and entomofauna of different wood habitats. Part I. Sampled habitats, Theoretical study of the pitfall method, survey of the captured taxa-Carabidae. Biol. Jaarb. Dodonaea 1975, 43, 179-196.

43. Lafage, D.; Maugenest, S.; Bouzillé, J.-B.; Pétillon, J. Disentangling the influence of local and landscape factors on alpha and beta diversities: Opposite response of plants and ground-dwelling arthropods in wet meadows. Ecol. Res. 2015, 30, 1025-1035. [CrossRef]

44. Rodriguez-Artigas, S.M.; Ballester, R.; Corronca, J.A. Factors that influence the beta-diversity of spider communities in northwestern Argentinean Grasslands. PeerJ 2016, 4, e1946. [CrossRef] 
45. Ávila, A.C.; Stenert, C.; Rodrigues, E.N.L.; Maltchik, L. Habitat structure determines spider diversity in highland ponds. Ecol. Res. 2017, 32, 359-367. [CrossRef]

46. Sebek, P.; Vodka, S.; Bogusch, P.; Pech, P.; Tropek, R.; Weiss, M.; Zimova, K.; Cizek, L. Open-grown trees as key habitats for arthropods in temperate woodlands: The diversity, composition, and conservation value of associated communities. For. Ecol. Manag. 2016, 380, 172-181. [CrossRef]

47. Carvalho, J.C.; Cardoso, P.; Crespo, L.C.; Henriques, S.; Carvalho, R.; Gomes, P. Biogeographic patterns of spiders in coastal dunes along a gradient of mediterraneity. Biodivers. Conserv. 2011, 20, 873-894. [CrossRef]

48. Foord, S.; Dippenaar-Schoeman, A.; Haddad, C.R. South African Spider Diversity: African Perspectives on the Conservation of a Mega-Diverse Group. In Changing Diversity in Changing Environment; Grillo, O., Venora, G.I., Eds.; InTech: Rijeka, Croatia, 2011; ISBN 978-953-307-796-3.

49. Magura, T.; Horváth, R.; Tóthmérész, B. Effects of urbanization on ground-dwelling spiders in forest patches, in Hungary. Landsc. Ecol. 2010, 25, 621-629. [CrossRef]

50. Alaruikka, D.; Kotze, D.J.; Matveinen, K.; Niemela, J. Carabid beetle and spider assemblages along a forested urban-rural gradient in southern Finland. J. Insect Conserv. 2002, 6, 195-206. [CrossRef]

51. Varet, M.; Burel, F.; Lafage, D.; Pétillon, J. Age-dependent colonization of urban habitats: A diachronic approach using carabid beetles and spiders. Anim. Biol. 2013, 63, 257-269. [CrossRef]

52. Tourinho, A.L.; Dias, S.C.; Lo-Man-Hung, N.F.; Pinto-da-Rocha, R.; Bonaldo, A.B.; Baccaro, F.B. Optimizing survey methods for spiders and harvestmen assemblages in an Amazonian upland forest. Pedobiologia 2018, 67, 35-44. [CrossRef]

(C) 2020 by the authors. Licensee MDPI, Basel, Switzerland. This article is an open access article distributed under the terms and conditions of the Creative Commons Attribution (CC BY) license (http://creativecommons.org/licenses/by/4.0/). 